\title{
SELEÇÃO DE GENÓTIPOS DE MIRTILEIRO OBTIDOS A PARTIR DE POLINIZAÇÃO ABERTA ${ }^{1}$
}

\author{
DORALICE LOBATO DE OLIVEIRA FISCHER ${ }^{2}$, JOSÉ CARLOS FACHINELLO ${ }^{3}$, \\ CLAUSE FÁTIMA DE BRUM PIANA ${ }^{4}$, VALMOR JOÃO BIANCHI ${ }^{5}$, NICÁCIA PORTELLA MACHADO ${ }^{6}$
}

RESUMO - No Brasil, as cultivares de mirtileiro, exploradas economicamente, foram introduzidas de outros países e, sendo assim, selecionadas em outras condições edafoclimáticas, podendo apresentar limitações para seu cultivo. Visando à obtenção de plantas superiores mais adaptadas para as condições brasileiras, realizou-se a seleção em três populações de mirtileiro de polinização aberta com o objetivo de obter progênies superiores. O material vegetal utilizado constituiu-se de 3.554 plantas, provenientes de sementes das cultivares Bluegem (1.212 plantas), Bluebelle (1.439 plantas) e Powderblue (903 plantas). O experimento foi conduzido em área previamente adubada, conforme análise de solo, em espaçamento de 30 x $30 \mathrm{~cm}$, com sistema de irrigação por aspersão. A seleção nas plantas das três populações foi realizada em três etapas (2007/2008, 2008/2009 e 2010/2011). No primeiro ciclo, realizou-se a seleção negativa, eliminando-se as plantas indesejáveis; no segundo, foi realizada a seleção positiva, quando foram selecionadas 20 plantas de cada uma das populações. Como critério de seleção, nos dois primeiros ciclos, foram usados os seguintes caracteres: vigor da planta, produção, estado fitossanitário, início de produção, presença de pruína na epiderme, tamanho e sabor do fruto. Ao final do segundo ciclo, as 20 plantas pré-selecionadas de cada população foram avaliadas, por um período de dois anos (2009/2010 e 2010/2011), registrando-se a produtividade das plantas e as variáveis químicas dos frutos. Com base nos resultados obtidos, pode-se concluir que 10 genótipos (BG5, BG2, BG3, BG6, PW3, PW5, PW1, BB10, BB5 e BB2) têm potencial para dar-se continuidade ao processo de seleção, pois apresentam bom desenvolvimento vegetativo, frutos de boa qualidade e de tamanho adequado ao mercado consumidor.

Termos para indexação: Vaccinium ashei Reade, mirtilo, produtividade.

\section{BLUEBERRY GENOTYPE SELECTION OBTAINED FROM OPEN POLLINATION}

ABSTRACT - Blueberry cultivars economically grown in Brazil were introduced from other countries, in which they were selected according different edaphoclimatic conditions and so it might impose some cultivation limitation in Brazil. In order to obtain superior progenies better adapted to Brazilian conditions, it was performed plant selection in three free polinization blueberry populations. The plant material consisted of 3,554 plants obtained from seeds from the cultivars Bluegem (1,212 plants), Bluebelle (1,439 plants) and Powderblue (903 plants). The experiment was performed in an area previously fertilized according to soil analysis, in a spacing of $30 \times 30 \mathrm{~cm}$, with sprinkler irrigation system. The selection was performed during three growing seasons $(2007 / 08,2008 / 09$ and 2010/11). In the first growing season it was made a negative selection, eliminating the undesirable plants; in the second, a positive selection was performed, where 20 plants were selected from each of the populations; and the third, also by positive selection, where ten plants were selected within each set of 20 plants previously selected in the second step. As the selection criteria, it was used the following characteristics for the first two growing seasons: plant vigor, production, plant health, early production, presence of bloom, fruit size and fruit flavor, the latter assessed by two trained individuals. At the end of the second growing season, the pre-selected 20 plants of each population were evaluated for a period of two years (2009/10 and 2010/11), recording productive parameters of these plants and chemical parameters of the fruits. The subjective consideration of these outcomes was an additional criterion used for the selection of the third growing season plants. It was noticed that the genotypes of the three cultivars of this study show yield and fruit size suitable to the market. Moreover, genotypes derived from the cultivars Bluegem and Powderblue have better sugar/acidity relationship. Based on the results obtained, it can be concluded that the genotypes BG5, BG2, BG3, BG6, PW3, PW5, PW1, BB10, BB2 and BB5 have the potential to continue the selection process, since they have good vegetative growth, fruit good quality and size appropriate to the consumer market.

Index terms: Vaccinium ashei Reade, blueberry, productivity.

1(Trabalho 299-13). Recebido em: 22-08-2013. Aceito para publicação em: 17-02-2014.

${ }^{2}$ Eng $^{\mathrm{a}}$. Agr., Dr ${ }^{\mathrm{a}}$., Prof ${ }^{\mathrm{a}}$ do IFSul-Rio-Grandense, Campus CaVG. Pelotas, RS. E-mail: doralicefischer@cavg.ifsul.edu.br ${ }^{3}$ Eng. Agr., Dr., Depto de Fitotecnia, FAEM, UFPel. C P354, CEP 96010-900, Pelotas, RS, E-mail: jfachi@ufpel.tche.br ${ }^{4}$ Bióloga, Dra , Centro de Desenvolvimento Tecnológico, UFPel, Pelotas-RS. E-mail: clausepiana@yahoo.com.br

${ }^{5}$ Eng. Agr., Dr, Depto de Botânica, Instituto de Biologia, UFPel, Pelotas, Rio Grande do Sul, Brasil. E-mail: valmorjb@yahoo.com.br

${ }^{6}$ Eng $^{\mathrm{a}}$. Agrícola, Doutora em Fruticultura de Clima Temperado, Universidade Federal de Pelotas.E-mail: nicacia@gmail.com 


\section{INTRODUÇÃO}

O mirtileiro é uma espécie perene, que pode ser propagada também por sementes, normalmente para fins de melhoramento. Suas flores apresentam várias características que favorecem a polinização cruzada, como pétalas soldadas entre si, formando uma campânula invertida com uma pequena abertura, que protege os estames da ação do vento, desfavorecendo a autopolinização. Além disso, as flores são aromáticas e possuem glândulas nectaríferas na base do estigma que atraem os insetos responsáveis pela polinização cruzada (FONSECA; OLIVEIRA, 2007).

Em plantas de polinização cruzada, o melhoramento pode ser realizado a partir da variabilidade disponível, tornando-se um método prático, de baixo custo e de fácil execução Essa estratégia tem sido muito utilizada na seleção de diversas fruteiras, como aceroleira (PAIVA et al., 1999), goiabeira-serrana (DUCROQUET et al., 2007), maracujazeiro (PIMENTEL et al., 2008; OLIVEIRA et al., 2008) e açaizeiro (OLIVEIRA; FARIAS NETO, 2008).

No Brasil, a grande maioria das cultivares de mirtileiro exploradas economicamente foram introduzidas, ou seja, foram selecionadas em outras condições edafoclimáticas, podendo apresentar limitações para a sua produção nas diferentes áreas de cultivo. Entretanto, desde que utilizados genótipos adaptados, existem condições favoráveis para o cultivo dessa espécie em várias regiões brasileiras com características de clima temperado, em áreas de solos bem drenados, com boa capacidade de retenção de água, ricos em matéria orgânica e pH de 4,2 a 5,5.

Visando à obtenção de plantas superiores com boas características qualitativas e quantitativas, e adaptadas às condições de solo e clima da região sul do Rio Grande Sul, realizou-se a seleção de genótipos de mirtileiro em três populações oriundas de polinização aberta.

\section{MATERIAL E MÉTODOS}

O trabalho foi conduzido a $31^{\circ} 33^{\prime} 04,77^{\prime}$ S, $52^{\circ} 23^{\prime} 50,46^{\prime \prime} \mathrm{O}$ e $110 \mathrm{~m}$ de altitude, no período de dezembro de 2005 a janeiro de 2011.

As plantas-matrizes que deram origem às populações foram provenientes de um matrizeiro constituído por oito cultivares provenientes de propagação vegetativa (Bluegem, Bluebelle, Powderblue, Climax, Briteblue, Woodard e Delite). Em dezembro de 2005, realizaram-se a seleção e a coleta dos frutos de maior tamanho das cultivares
Bluebelle, Powderblue e Bluegem. As sementes extraídas desses frutos deram origem a 3.554 mudas, sendo 1.212 da cultivar Bluegem, 1.439 da Bluebelle e 903 da Powderblue.

No início do mês de fevereiro de 2007, as mudas com aproximadamente um ano de idade foram transplantadas para o campo experimental, agrupadas por cultivar materna, formando três populações. A área experimental foi previamente preparada $\mathrm{e}$ adubada, conforme análise de solo. O plantio foi realizado em espaçamento adensado de $30 \times 30 \mathrm{~cm}$, sob sistema de irrigação por aspersão.

O clima local, segundo classificação de Köppen, é do tipo Cfa (KUINCHTNER; BURIOL, 2001), com temperatura média anual de $17,8{ }^{\circ} \mathrm{C}$, umidade relativa média anual de $80,7 \%$ e precipitação pluvial média anual de $1.367 \mathrm{~mm}$. O solo da região é do tipo Argissolo Vermelho-Amarelo, segundo o Sistema Brasileiro de Classificação (SANTOS et al., 2006), e o pH da área experimental é 4,5, conforme a análise de solo. Durante o período de desenvolvimento das plantas, foram empregadas as práticas culturais de rotina. $\mathrm{O}$ acúmulo de horas de frio e as médias das temperaturas máximas e mínimas, no período de 2005 a 2011, são apresentados na Tabela 1 .

O método utilizado para selecionar as plantas, nas três populações, foi realizado em três etapas (2007/2008, 2008/2009 e 2010/2011). No primeiro ciclo, realizou-se a seleção negativa, eliminando-se as plantas indesejáveis; no segundo, foi realizada a seleção positiva, quando foram selecionadas 20 plantas de cada uma das populações; e no terceiro, também por seleção positiva, foram selecionadas dez plantas de cada conjunto de 20 , resultante da etapa anterior.

Como critério de seleção, para as duas primeiras etapas, foram utilizados os seguintes caracteres: vigor da planta, produção de frutos, estado fitossanitário, início de produção, presença de pruína na epiderme dos frutos, tamanho e sabor do fruto, esta última avaliada por dois avaliadores diferentes. Outras características secundárias observadas foram formato da copa, coloração, formato e tamanho das folhas, das flores e dos frutos, distância de entrenós dos ramos e formato dos cachos.

Ao final da segunda etapa, as 60 plantas selecionadas foram avaliadas, por um período de dois anos (2009/2010 e 2010/2011), registrando-se variáveis relativas à produção e variáveis químicas dos frutos. A consideração subjetiva dos resultados dessa avaliação foi um critério adicional utilizado para a seleção de plantas na terceira etapa.

As variáveis produtivas da planta foram: 
produção total de frutos, produção de frutos grandes e médios, e produção de frutos pequenos por planta, medidas em kg. Para classificar os frutos, foram utilizados dois baldes, um com furos de $14,7 \mathrm{~mm}$ de diâmetro, para separar os frutos grandes, e outro com furos de 12,5 mm de diâmetro, para separar os frutos médios dos frutos pequenos. As variáveis químicas dos frutos analisadas foram: o teor de sólidos solúveis (SS), em ${ }^{\circ}$ Brix, determinados com auxílio de refratômetro digital de bancada, acidez titulável (AT), em \% de ácido cítrico, por meio da diluição de $10 \mathrm{~mL}$ de suco puro em $90 \mathrm{~mL}$ de água destilada e titulação com $\mathrm{NaOH} 0,01 \mathrm{~N}$ até atingir o $\mathrm{pH}$ de 8,1 , e a relação $\mathrm{SS} / \mathrm{AT}$, determinada pela razão entre os dois constituintes. Essas variáveis foram mensuradas a cada colheita, a partir de uma amostra de 25 a 30 frutos.

Para a comparação das características das progênies com as das cultivares-mães, foram escolhidos ao acaso, no matrizeiro, três clones de cada cultivar-mãe, marcados e avaliados segundo as variáveis morfológicas e de produção.

A análise estatística consistiu em análise descritiva dos dados por meio de medidas descritivas e gráfico de caixa ("box plot"), e análise de correlação entre variáveis.

\section{RESULTADOS E DISCUSSÃO}

Em 2007/2008, durante o primeiro período de produção das progênies, iniciou-se o processo de seleção negativa. Nesta fase, foram eliminadas todas as plantas improdutivas, com baixo vigor, frutos de sabor indesejável, pequenos, de baixa qualidade, com tendência a rachaduras, ausência de pruína e pouco atrativos. Resultaram 459 plantas selecionadas, das quais 208 oriundas da cultivar Bluegem, 172 da Bluebelle e 79 da Powderblue. Os índices de seleção para as populações das cultivares Bluegem, Bluebelle e Powderblue foram, respectivamente, $17,16 \%$, $19,05 \%$ e $5,49 \%$.

O segundo período de seleção (2009/2010) resultou na seleção de 20 plantas de cada progênie. Nesta fase, os índices de seleção foram 9,62\%, $11,63 \%$ e $25,32 \%$, para as populações de Bluegem, Bluebelle e Powderblue, respectivamente.

Nas Figuras de 1 a 6, são apresentados os gráficos de caixa que descrevem o comportamento das cultivares-mães, avaliados no matrizeiro, e das 20 plantas selecionadas de cada progênie, para todas as variáveis analisadas. Esses gráficos possibilitam a análise do comportamento de plantas da progênie e clones da cultivar-mãe, dentro de cada ano e entre os anos.
De modo geral, verifica-se, para todas as variáveis, que o comportamento dos clones da plantamãe variou entre os anos, evidenciando o efeito de ano, isto é, o efeito das características de ambiente que variam de um ano para o outro. Comparandose as três cultivares-mães, verificou-se que o efeito de ano também variou entre elas, caracterizando a interação entre cultivar e ano.

\section{Variáveis de produção}

Considerando que existe uma diferença de cinco anos entre as plantas-matrizes e as progênies, era de se esperar uma diferença expressiva na comparação dos dois grupos. Por essa razão, esperava-se que plantas da cultivar-mãe, com sete anos de idade em 2009, tivessem um comportamento superior ao das plantas da progênie, com menos de dois anos de idade na mesma época. De fato, a superioridade produtiva das plantas-mãe em relação às progênies foi observada, em 2009/2010, para as três cultivares e, mais expressivamente, para a cultivar Powderblue (Figura 1).

Em 2010/2011, entretanto, a progênie da cultivar Bluegem, com quase três anos, obteve produção de frutos próxima à da cultivar-mãe, que, aos oito anos, produziu entre $0,767 \mathrm{~kg}$ e $1,334 \mathrm{~kg}$ por planta. As plantas mais produtivas da progênie de Bluegem produziram 1,341 kg e 1,274 kg. Neste ano, as progênies das cultivares Powderblue e Bluebelle tiveram seus máximos $(1,412 \mathrm{~kg}$ e 1,415 $\mathrm{kg}$, respectivamente) próximos dos mínimos da cultivar- mãe (1,604 kg e 1,462 kg, respectivamente).

A produção entre as plantas das cultivares variou de 1,5 a 6,8 $\mathrm{kg}$ por planta, em 2009, e de 0,7 a $3,9 \mathrm{~kg}$, em 2010. Entre as progênies, no entanto, a produção variou de 0,2 a $1,7 \mathrm{~kg}$, em 2009 , e de 0,2 a $1,5 \mathrm{~kg}$, em 2010, evidenciando uma provável estabilização da produção.

Yu et al. (2006) testaram a adaptação de dez cultivares, incluindo as do grupo rabbiteye, e obtiveram produção de 0,5 a $1,0 \mathrm{~kg}$ por planta no terceiro ano após o plantio, e de 2,0 a 3,0 kg no quarto ano, entrando em plena produção no quinto ano. Ao avaliar três safras consecutivas, Antunes et al. (2008) verificaram grandes diferenças entre as produções de sete cultivares de mirtileiro do grupo rabbiteye, com uma variação de 0,35 a $1,63 \mathrm{~kg}$ por planta. Esses autores supõem que essas diferenças de produção sejam consequência da polinização e de fatores intrínsecos à própria adaptação das plantas, como o requerimento de baixas temperaturas e as variações climáticas locais. As cultivares Bluegem, Powderblue e Bluebelle apresentaram produção média de 1,25; 1,02 e 1,63 kg por planta, respectivamente. 
Na Figura 1, observa-se que, em 2010/2011 houve um decréscimo da produção da cultivar e da progênie de Bluegem e da cultivar Powderblue, e um baixo incremento nas demais progênies. Esses resultados podem estar relacionados à ocorrência de Botrytis, pois verificou-se a campo que a incidência foi maior nas plantas das populações Bluegem e Powderblue, provavelmente, devido ao adensamento de plantas dentro das populações, coincidentemente em decorrência da seleção negativa, e nestas duas populações havia plantas mais agrupadas. Outro fator relevante é a localização das cultivares de Powderblue e Bluegem no matrizeiro, que ficam na parte mais baixa e mais próxima da área de plantio das progênies, por serem plantas já estabelecidas, possivelmente pode ter sido fonte de foco de algumas doenças fúngicas. Esses fatores podem ter sido determinantes nos rendimentos de produção.

Por meio desses resultados, observa-se que as progênies selecionadas no presente trabalho são promissoras, podendo alcançar produções satisfatórias quando atingirem a idade de plena produção, do sétimo ao oitavo ano.

Quanto à variável produção de frutos grandes e médios, e produção de frutos pequenos, as plantas de cada cultivar apresentaram comportamento similar durante os dois anos. As cultivares Bluegem e Powderblue apresentaram maior produção total, maior produção de frutos médios e grandes, e maior produção de frutos pequenos, em 2009/2010, decrescendo em 2010/2011. Efeito inverso foi observado para 'Bluebelle', nos dois anos.

Para as progênies, quando comparados os dois anos, observou-se que, em 2010/2011, diminuiu a produção de frutos médios e grandes (Figura 2), e aumentou a produção de frutos pequenos (Figura 3). Yu et al. (2006) observaram comportamento semelhante em plantas do grupo higbush, as quais, com o passar dos anos, apresentaram redução no peso médio dos frutos, provavelmente em decorrência da estabilização da produção, tendo como consequência maior competição.

Considerando a idade das progênies e a variação do tamanho dos frutos de um ano para o outro entre as cultivares no presente trabalho, é possível que o comportamento diferenciado das plantas deva-se também a fatores genéticos e, principalmente, de ambiente, uma vez que, durante este ciclo, o acúmulo de horas de frio foi de 330, bem abaixo dos seis últimos anos, que variaram de 474 a 780 horas. De acordo com Serrado et al. (2008), a produção e o período de colheita do mirtileiro aumentam regularmente com o passar dos anos, atingindo a estabilidade do sétimo ao oitavo ano após o plantio.

$\mathrm{Na}$ maioria dos genótipos, observou-se que os frutos apresentam maior tamanho nas primeiras colheitas, decrescendo ao final desse período. Em um número restrito de genótipos, com produção de frutos mais uniformes, o tamanho permaneceu praticamente o mesmo até o término da colheita.

\section{Variáveis químicas dos frutos}

Os dados referentes às variáveis químicas dos frutos são apresentados nas Figuras 4; 5e 6. Na Figura 4, são apresentados os resultados referentes à variável teor de sólidos solúveis. Assim como registrado para o $\mathrm{pH}$ da polpa, em ambos os ciclos de produção, verificou-se pouca variação (de 12,4 a 13,9 ${ }^{\circ}$ Brix) para as três cultivares-mães. As progênies, por sua vez, apresentaram aumento uniforme no teor de sólidos solúveis de um ano para o outro. Os teores medianos observados em 2009/2010 e 2010/2011 foram, respectivamente, 12,3 e $14,5{ }^{\circ}$ Brix, para Bluegem, 12,4 e 14,2 ${ }^{\circ}$ Brix, para Powderblue e 12,6 e $14,1^{\circ}$ Brix, para Bluebelle. Essa variação possibilita a seleção de genótipos com maiores teores de SS entre as progênies.

O comportamento da variável relação entre sólidos solúveis e acidez titulável (SS/AT), conforme pode ser observado na Figura 6, variou entre cultivares. De 2009/2010 para 2010/2011, as três cultivares reduziram seus valores, enquanto as progênies apresentaram efeito inverso, com medianas de 18,8 e 23,6 (Bluegem), 18,2 e 20,0 (Powderblue) e de 16,5 e 17,7 (Bluebelle). Os valores verificados neste trabalho são superiores aos encontrados por Rodrigues et al. (2007) para as cultivares Bluegem, Powderblue e Bluebelle, que foram de 9,53; 14,74 e 13,69, respectivamente. Possivelmente, essas diferenças devam-se ao estádio de maturação dos frutos, devido à frequência e até mesmo à escolha de frutos ainda de vez no momento da colheita. Segundo Mainland e Cline (2002), o sabor dos frutos do grupo rabbiteye melhora se colhidos a cada sete ou dez dias, o que permite obter frutos com o máximo de sabor.

A ocorrência de valores elevados da relação SS/AT dos frutos nas progênies, em 2010/2011, pode ser decorrente do aumento no conteúdo de sólidos solúveis dos frutos naquele ano. A progênie de Bluegem, quando comparada às demais, destacouse por apresentar maior teor de SS em 2010/2011. De acordo com Pinto et al. (2003), a relação SS/AT é uma das formas mais utilizadas para a avaliação do sabor, sendo mais representativa que a medição isolada do teor de açúcares ou da acidez.

O terceiro ciclo de seleção (2010/2011), que também foi baseado nos resultados da avaliação 
dessas variáveis durante os dois anos, resultou em um conjunto de 30 plantas, sendo dez de cada população. Na Tabela 2, essas 30 plantas selecionadas são caracterizadas quanto às variáveis de produção e características químicas dos frutos.

Verifica-se que genótipos selecionados da progênie da cultivar Bluegem foram os que apresentaram as maiores produções e as mais consistentes nos dois anos. As produções médias dos cinco genótipos mais produtivos de cada grupo foram: $1,17 \mathrm{~kg}$ para os descendentes de Bluegem, $0,85 \mathrm{~kg}$ para descendentes de Powderblue e $0,75 \mathrm{~kg}$ para descendentes de Bluebelle. No primeiro ciclo de produção (2009/2010), os genótipos BG5, BG2, BG6, BG3, PW3, PW5, PW1, BB10, BB2, BB5 e BB6 destacaram-se por apresentar alta produção de frutos grandes e médios.
Na Tabela 2, observa-se, também, que a maioria dos genótipos descendentes da cultivar Bluegem apresenta valores desejáveis para a relação SS/AT. As médias dos genótipos por grupo foram: 22,5 para descendentes de Bluegem, 20,17 para descendentes de Powderblue e 16,75 para descendentes de Bluebelle. Destacam-se com as maiores médias, considerando os dois ciclos, os genótipos BG3 $(30,3)$, PW9 $(24,9)$, PW1 $(24,8)$, BG9 $(24,6)$, PW5 $(24,5)$ e BG2 $(24,2)$. Esses resultados evidenciam que entre as plantas selecionadas há genótipos promissores (Figura 7), com um bom desenvolvimento vegetativo, e frutos de qualidade, podendo alcançar produções satisfatórias quando atingirem a idade de plena produção.

TABELA 1- Acúmulo de horas de frio (abaixo de $7,2^{\circ} \mathrm{C}$ ) e média das temperaturas $\left({ }^{\circ} \mathrm{C}\right.$ ) máximas e mínimas, nos meses de maio a setembro dos anos de 2005 a 2011, na sede da Estação Experimental da Embrapa Clima Temperado em Pelotas-RS, a $31^{\circ} 37^{\prime} 15,57^{\prime \prime}$ S, 52 $31^{\circ}$ ' 30,77” W e 164 $m$ de altitude.

\begin{tabular}{c|c|c|c}
\hline Ano & Horas de frio & Temperatura máxima & Temperatura mínima \\
\hline 2005 & 276 & 20 & 10 \\
2006 & 474 & 19 & 9 \\
2007 & 780 & 17 & 8 \\
2008 & 479 & 18 & 9 \\
2009 & 502 & 19 & 9 \\
2010 & 330 & 19 & 11 \\
2011 & 409 & 18 & 9 \\
\hline
\end{tabular}




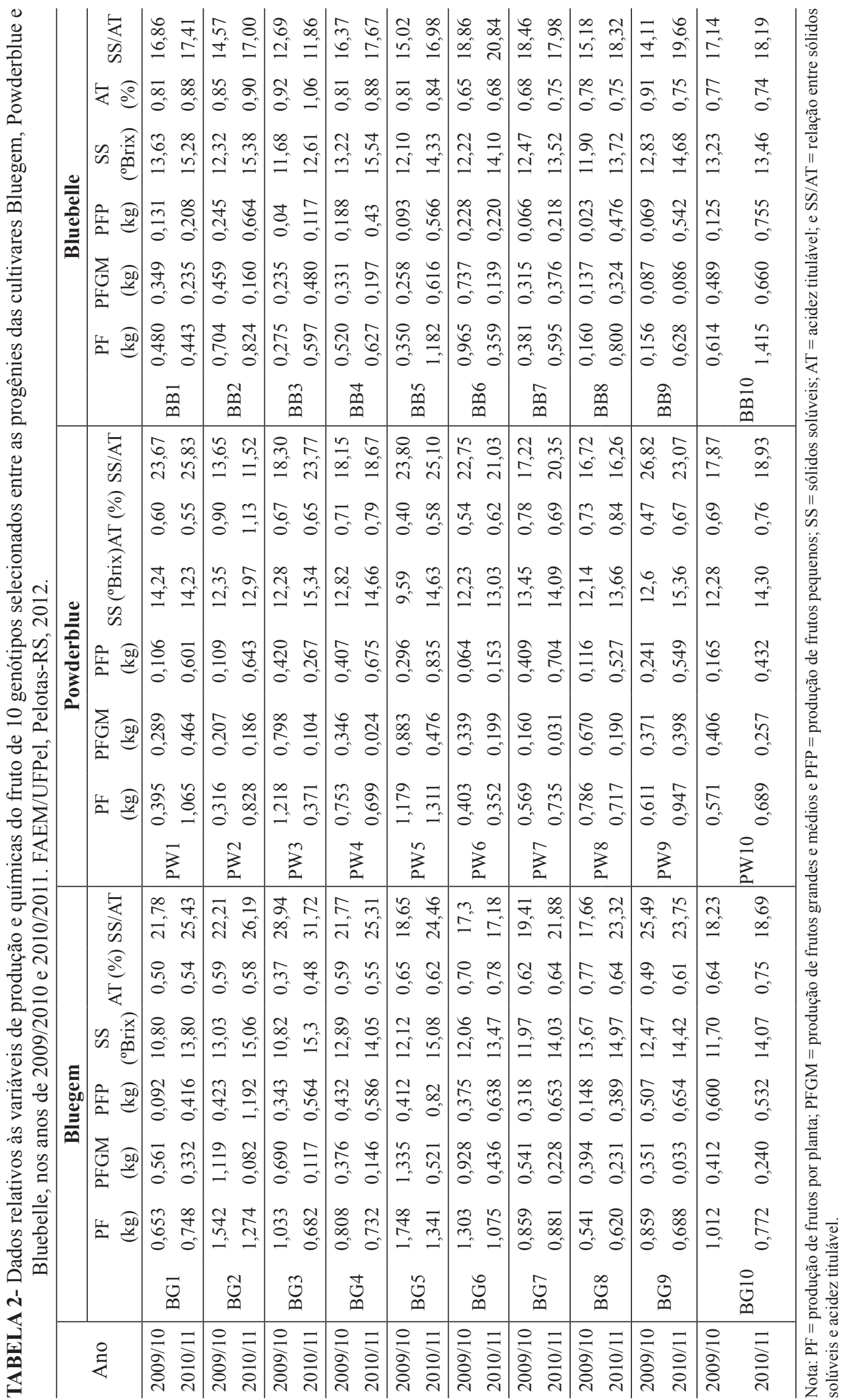




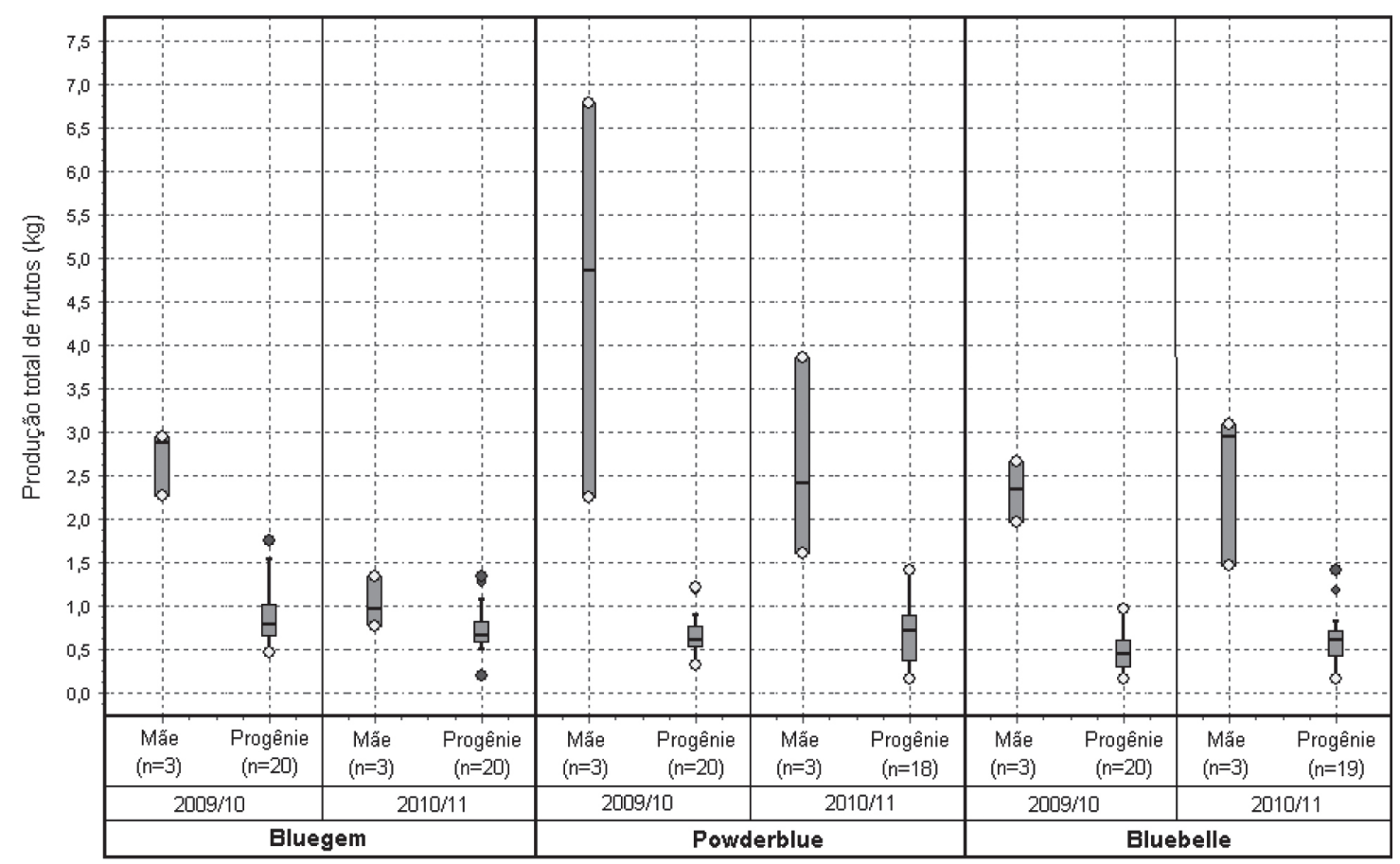

FIGURA 1- Distribuição da variável produção total de frutos (kg), por cultivar, nos anos de 2009/2010 e 2010/2011. FAEM/UFPel, Pelotas-RS, 2012.

Nota: $\mathrm{n}$ indica número de plantas; ponto amarelo indica valor extremo; ponto vermelho indica valor atípico ("outlier").

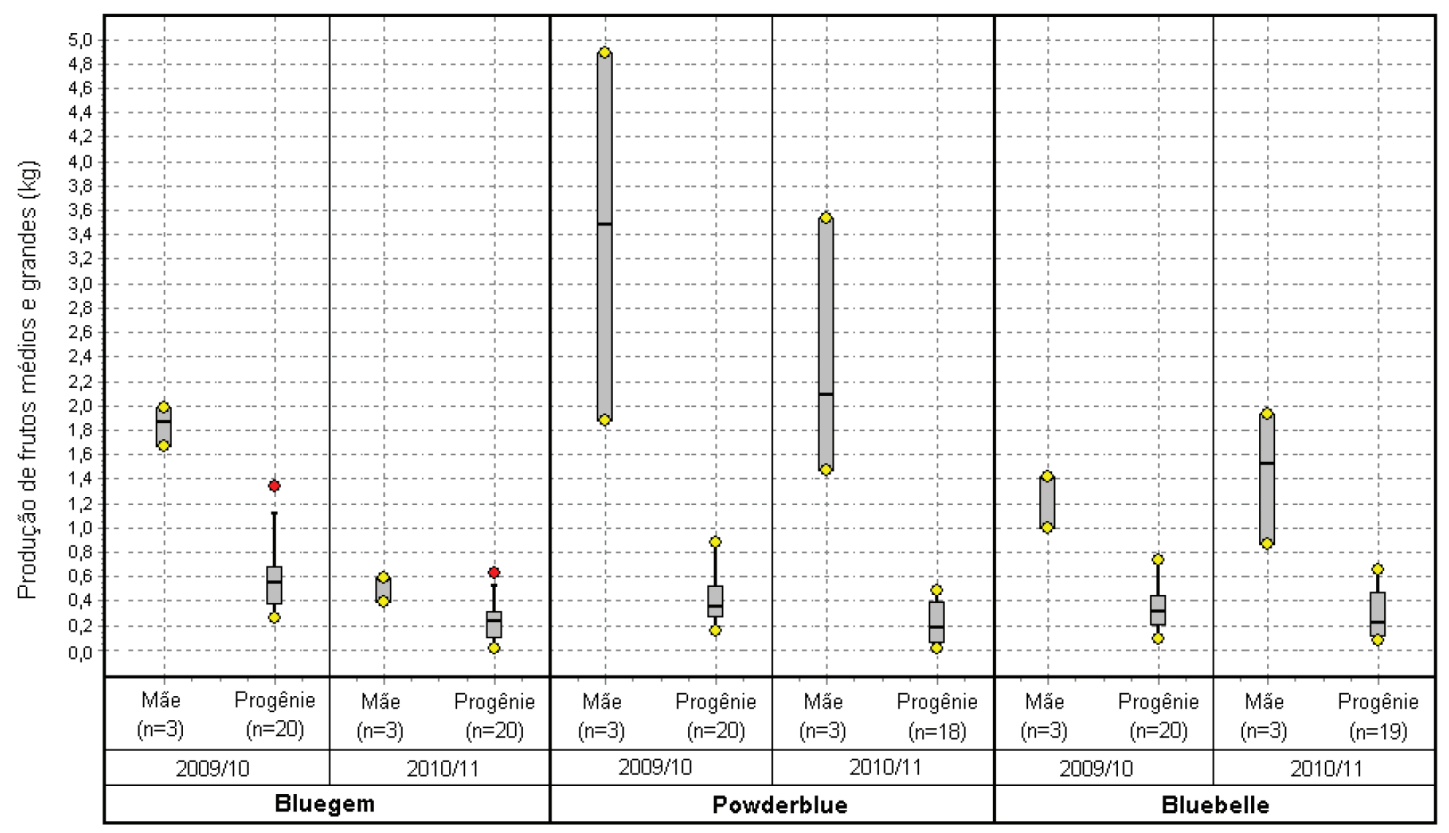

FIGURA 2- Distribuição da variável produção de frutos médios e grandes $(\mathrm{kg})$, por cultivar, nos anos de 2009/2010 e 2010/2011. FAEM/UFPel, Pelotas-RS, 2012. 


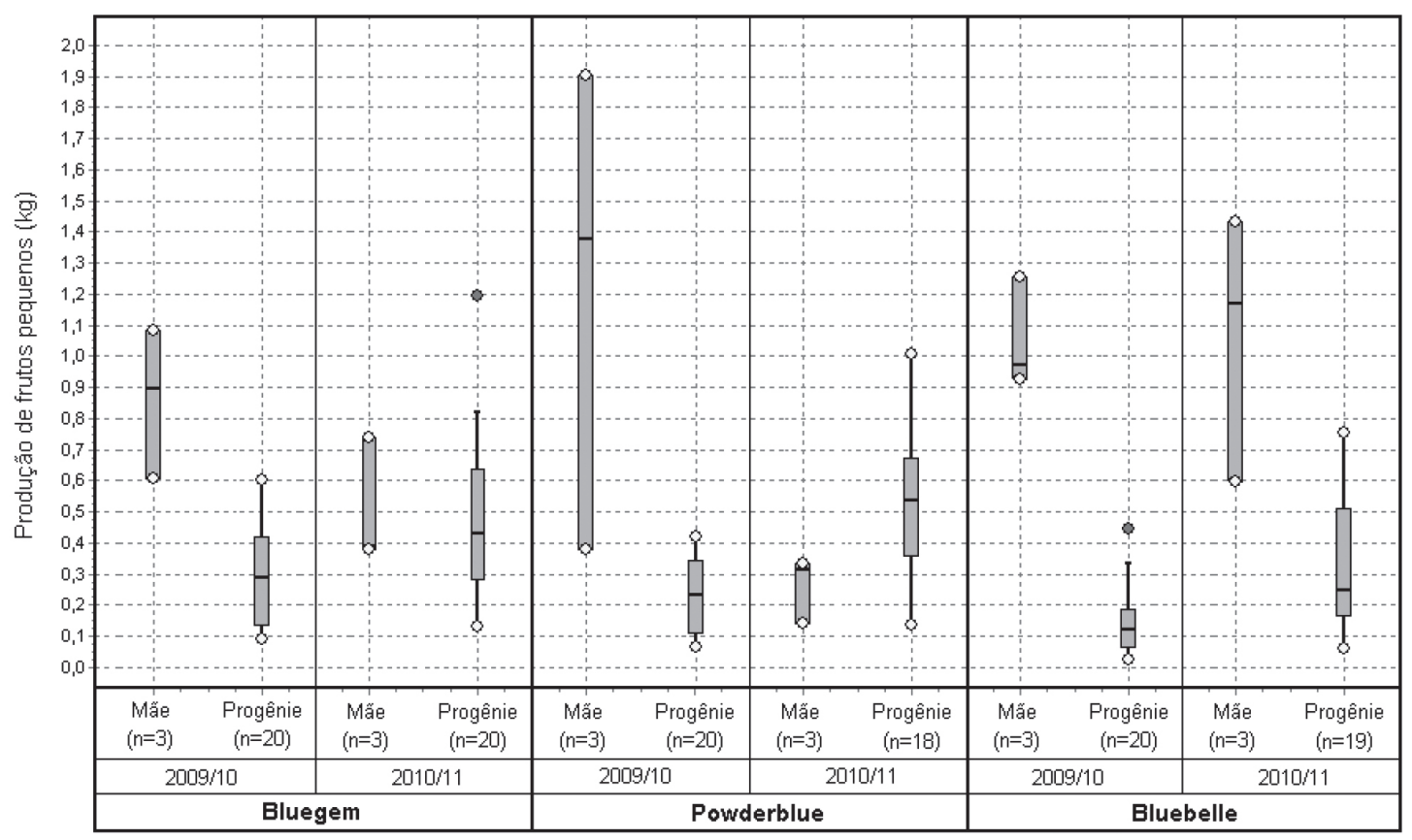

FIGURA 3- Distribuição da variável produção de frutos pequenos (kg), por cultivar, nos anos de 2009/2010 e 2010/2011. FAEM/UFPel, Pelotas-RS, 2012.

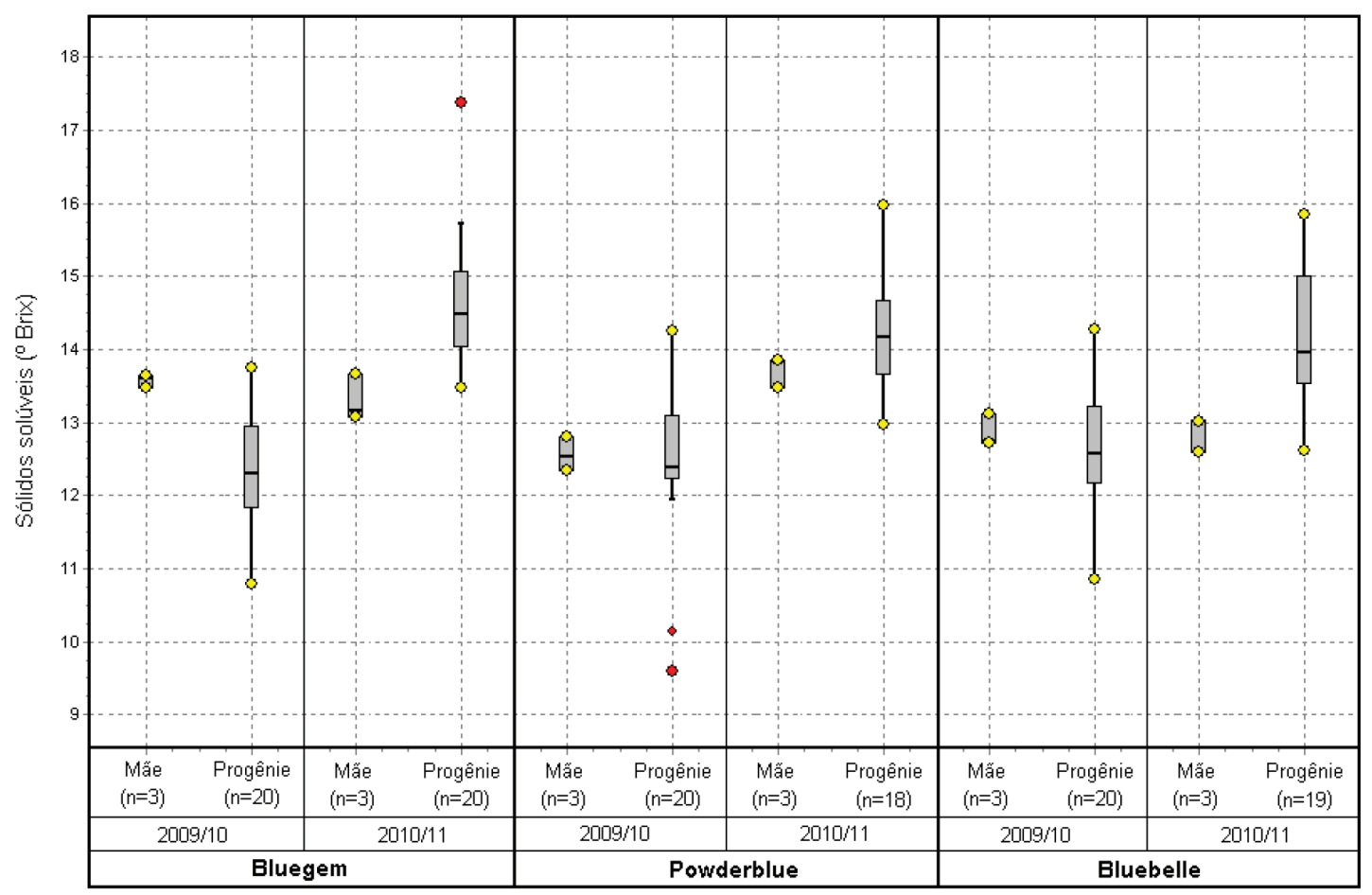

FIGURA 4- Distribuição da variável teor de sólidos solúveis do fruto ( ${ }^{\circ}$ Brix), por cultivar, nos anos de 2009/2010 e 2010/2011. FAEM/UFPel, Pelotas-RS, 2012. 


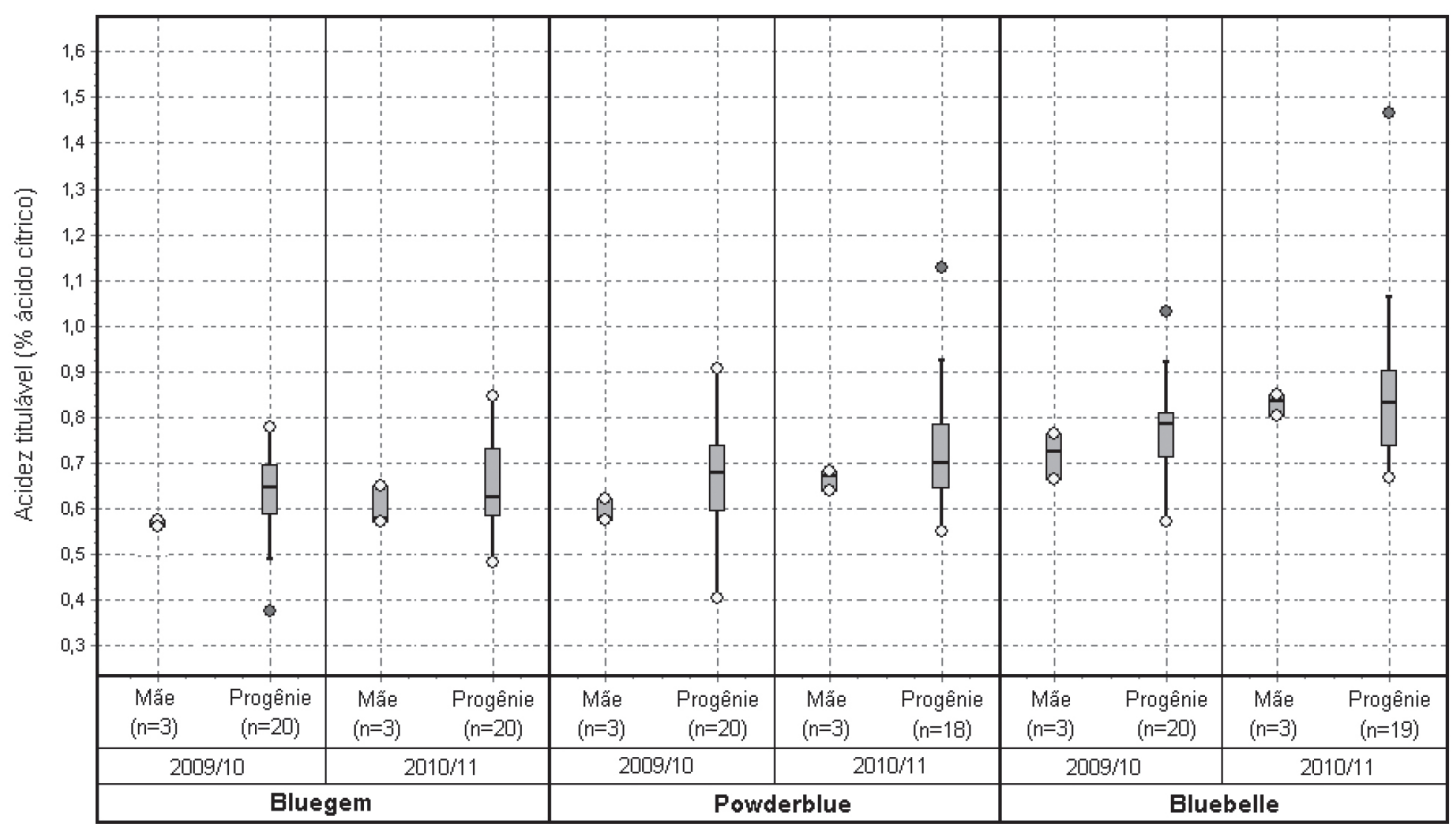

FIGURA 5- Distribuição da variável acidez titulável do fruto (\% de ácido cítrico), por cultivar, nos anos de 2009/2010 e 2010/2011. FAEM/UFPel, Pelotas-RS, 2012.

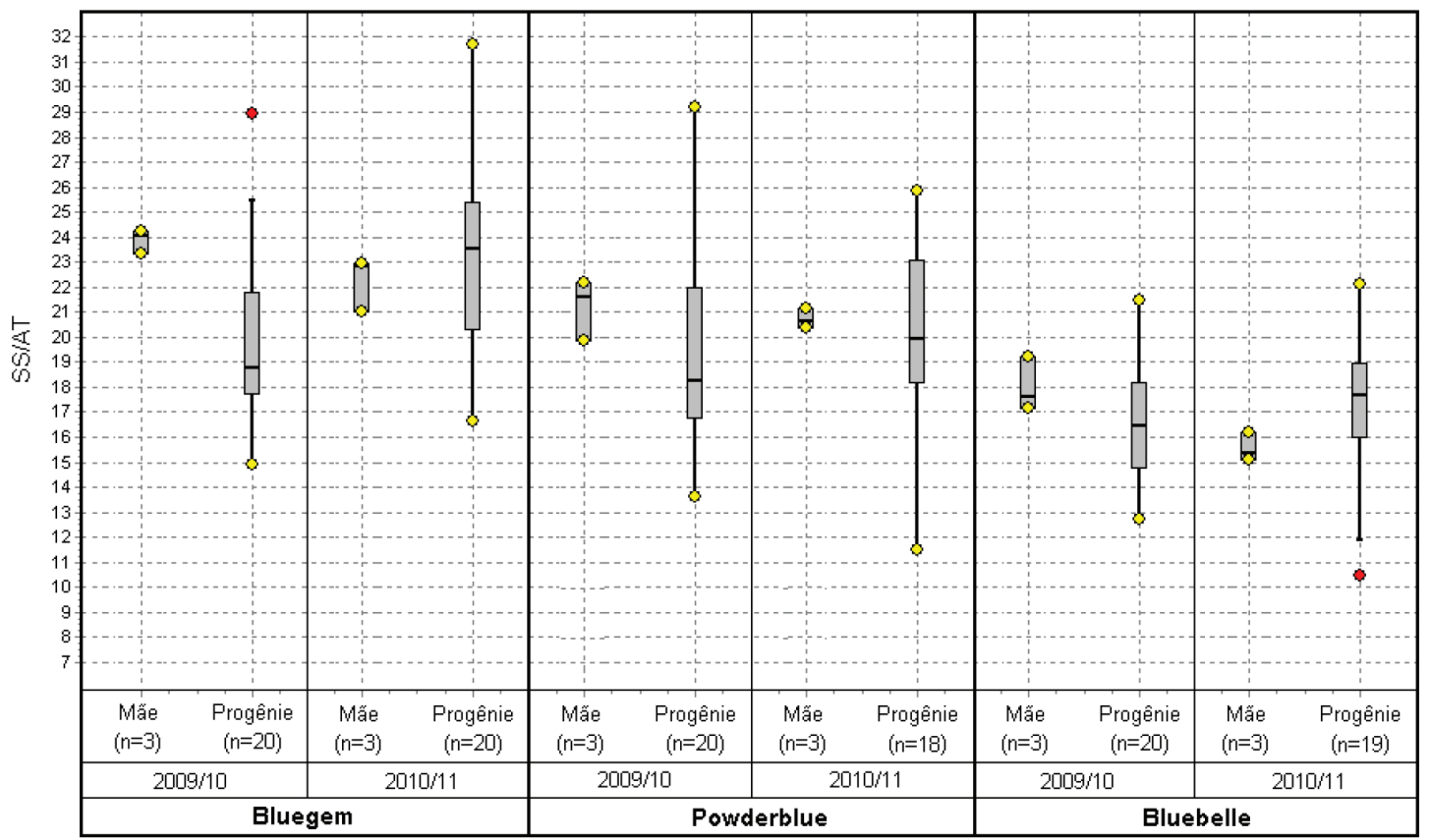

FIGURA 6- Distribuição da variável SS/AT do fruto, por cultivar, nos anos de 2009/2010 e 2010/2011. FAEM/UFPel, Pelotas-RS, 2012. 

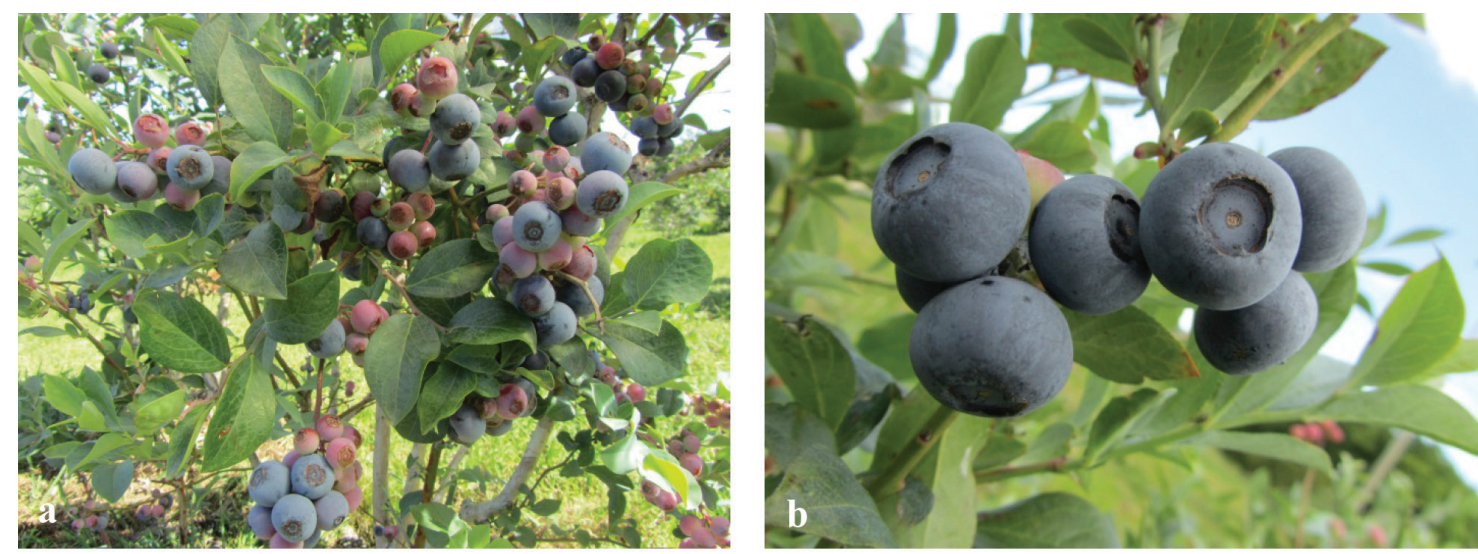

FIGURA 7- Aspectos morfológicos dos frutos de genótipos das cultivares Bluegem (a) e Powderblue (b). FAEM/ UFPel, Pelotas-RS, 2013.

\section{CONCLUSÕES}

Com base nos resultados obtidos, pode-se concluir que dez genótipos (BG5, BG2, BG3, BG6, PW3, PW5, PW1, BB10, BB5 e BB2) têm potencial para dar-se continuidade ao processo de seleção, pois apresentam bom desenvolvimento vegetativo, frutos de boa qualidade e de tamanho adequado ao mercado consumidor.

\section{REFERÊNCIAS}

ANTUNES, L.E.C.; GONÇALVES, E.D.; RISTOW, N.C.; CARPENEDO, S.; TREVISAN, R. Fenologia, produção e qualidade de frutos de mirtilo. Pesquisa Agropecuária Brasileira, Brasília, v.43, n.8, p.1011-1015, 2008.

DUCROQUET, J.P.H.J.; SANTOS, K.L. dos; ANDRADE, E.R. de; BONETI, J. I. da S.; BONIN, V.; NODARI, R. O. As primeiras cultivares brasileiras de goiabeira-serrana: Agropecuária Catarinense, Florianópolis, v. 20, n.2, p.77-80, 2007.

FONSECA, L.L. da; OLIVEIRA, P.B. de. A planta de mirtilo: morfologia e fisiologia. 2007. 23p. (Divulgação Agro, 556)

KUINCHTNER, A.; BURIOL, G. A. Clima do Estado do Rio Grande do Sul segundo a classificação climática de Köppen e Thornthwaite. Disciplinarum Scientia, Santa Maria, v.2, p.171-182, 2001.
MAINLAND, C. M.; CLINE, W. O. Blueberry production for local salesand small pick-yourown operators. North Carlona: State University. Disponível em: < $\underline{\text { http://www.ces.ncsu.edu/depts/ }}$ hort/hil/hil-202.html >. Acesso em: 15 jan. 2012.

OLIVEIRA, M. do S.P. de; FARIAS NETO, J.T. Seleção massal em açaizeiros para a produção de frutos. Revista Brasileira de Ciências Agrárias, Recife, n.49, p.145-156, 2008.

OLIVEIRA, E.J. de; SANTOS, V. da S.; LIMA, D.S. de; MACHADO, M.D.; LUCENA, R. S.; MOTTA, T.B.N.; CASTELlEN, M. da S. Seleção em progênies de maracujazeiro-amarelo com base em índices multivariados. Pesquisa Agropecuária Brasileira, Brasília, v.43, n.11, p.1543-1549, 2008.

PAIVA, J.R. de; ALVES, R.E.; CORREA, M.A.P.F.; FREIRE, das C.O.; BRAGA SOBRINHO, R. Seleção massal de acerola em plantio comercial. Pesquisa Agropecuária Brasileira, Brasília, v.34, n.3, p.505511, 1999.

PIMENTEL, L.D.; STENZEL, N.M.C.; CRUZ, C.D.; BRUCKNER, C.H. Seleção precoce de maracujazeiro pelo uso da correlação entre dados de produção mensal e anual. Pesquisa Agropecuária Brasileira, Brasília, v.43, n.10, p.1303-1309, 2008.

PINTO, W.S.; DANTAS, A.C.V.L.; FONSECA, A.A.O.; LEDO, C.A. da S.; JESUS, S.C. de; CALAFANGE, P.L.P.; ANDRADE, E.M. Caracterização física, físico-química e química de frutos de genótipos de cajazeiras. Pesquisa Agropecuária Brasileira, Brasília, v. 38, n.9, p. 1059-1066, 2003. 
RODRIGUES, S.A.; GULARTE, M.A.; PEREIRA, E.R.B.; BORGES, C.D.; VENDRUSCULO, C.T. Influência da cultivar nas características físicas, químicas e sensoriais de topping de mirtilo. Revista Brasileira de Tecnologia Agroindustrial, Campinas, v.1, n.1, p.9-29, 2007.

SANTOS, H.G.; JACOMINE, P.K.T.; ANJOS, L.H.C.; OLIVEIRA, V.A.; OLIVEIRA, J. B.; COELHO, M.R.; LUMBRERAS, J.F.; CUNHA, T.J.F. (Ed.). Sistema brasileiro de classificação de solos. 2. ed. Rio de Janeiro: Embrapa Solos, 2006. $306 \mathrm{p}$.
SERRADO, F.; PEREIRA, M.; FREITAS, S.; MARTINS, S.; DIAS, T. Mirtilos: guia de boas práticas para produção, promoção e comercialização. Portugal: Greca Artes Gráficas, 2008. 80p.

YU, H.; He, S.; GU, Y.; WANG, C.; WU, W. Introduction of Rabbiteye Blueberries to the Southern Part of China. Acta Horticulturae, The Hague, 715, p. 261-266, 2006. 